ORIGINAL ARTICLE

\title{
Effect of Basil Seed and Chia Seed Extracts on Blood Lipid Profile
}

\author{
SIDRA MUNIR ${ }^{1}$, SANA KHURSHID ${ }^{2}$, QAMAR JAVED IQBAL ${ }^{3}$, NASIR IQBAL $^{4}$, ZAINAB MASOOD $^{5}$

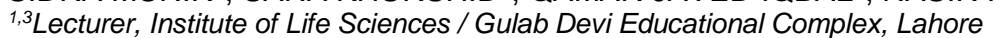 \\ ${ }^{2}$ Institute of Molecular Biology and Biotechnology, The University of Lahore, \\ ${ }^{4}$ MS Zoology, Lahore College Women University, Lahore \\ ${ }^{5}$ Associate Professor Cardiology/AzraNaheed Medical College, Lahore \\ Correspondence to Dr. Sidra Munir, Email: ,cydrahmuneer@gmail.com Contact: +92-333-6067167
}

\begin{abstract}
Background: Basil and Chia seeds contain higher nutritive values like vitamin, carbohydrates, Omega-3 oil and other dietary fibers. With all these rich dietary benefits these seeds regulate necessary health conditions and maintain body weight. Ocimumbasilicum (Basil) plant have been known to contain properties of weight loss, better digestion and other health benefits.

Aim: To check the Basil seed against hyperlipidemia in mice with Chia seeds.

Methodology: In this research, the effect of both seeds extract on body weight and plasma lipid profile were estimated in Albino mice after raising their cholesterol levels by high fatty diet. The experiments were performed in different groups like normal control, standard control, hyperlipidemia group and four groups of diet supplemented chia or basil seeds with two different doses.

Results: The biochemical analysis revealed that the supplementation of Basil seeds (400mg/kg/day) significantly lowered the levels of total plasma cholesterol, lipoproteins and triacylglycerol. Moreover, histopathological analysis of vital organs like kidneys, heart reported no toxicity.

Conclusion: Extracts of Chia and Basil seeds have shown controlling effects over the given parameters in the blood and weights of the animals and these may have potential to control high fat diet-induced hyperlipidemia when taken as dietary supplements.
\end{abstract}

Keywords: Cholesterol, Hyperlipidemia, Ocimumbasilicum, Salvia hispanica

\section{INTRODUCTION}

Globally, non-communicable diseases like diabetes, cancer and cardiovascular diseases are responsible for three in five deaths. Among the risk factor of these diseases are hypertension, high cholesterol and overweight ${ }^{1}$. Experiments on human and rodents have shown that high dietary fat consumption supports the development of hyperlipidemia and/or obesity by change in cholesterol and triglyceride levels of tissue and blood. Herbal treatments have always been there in domestic practices and customs, they are still used in rural lifestyles as primary cures or aids. As far as herbal cures are concerned turmeric, garlic and ginger were said to have healing properties for diseases like cancer. In sub-continent, use of these as spices is very common on daily basis ${ }^{2-3}$.

Basil seed (Ocimumbasilicum) also belongs to Mint family, Lameaceae known as Great Basil. The name Basil comes from Latin 'Basilius' which means 'Royal or Kingly plant'. The Basil plants are native to tropical regions of Africa and Southeast Asia 4 . Chia seeds (Salvia hispanica) belong to a flowering plant of Mint family, Lamiaceae. S. hispanica is one of two plants that are locally called as Chia, the other one is Salvia columbariae. The word 'Chia' is actually derived from Aztec word 'chian' which means 'oily', as, $S$. hispanica is rich in Omega-3 oil. It is native to Mexico, South America and Guatemala. It is a pseudocereal that possesses hydrophilic property, used in smoothies, other drinks and cuisines. Chia seeds remained under discussion for their nutritive values ${ }^{5}$.Nutritive values of chia holds amount per 100 grams: total Fat $31 \mathrm{~g}(47 \%)$,

Received on 23-02-2021

Accepted on 21-05-2021 with high percentage of polyunsaturated and monosaturatedfat (approximately $26 \mathrm{~g}$ ), trans fat $0.1 \mathrm{~g}$, potassium $407 \mathrm{mg}(11 \%)$, dietary fiber $34 \mathrm{~g}(136 \%)$, protein $17 \mathrm{~g}(34 \%)$, iron (42\%), magnesium (83\%) vitamin $\mathrm{A}$ and $\mathrm{C}\left(1 \%\right.$ and $2 \%$ respectively), calcium $(63 \%)^{6}$. Chia and Basil seeds contain $\alpha$-linolenic acid, omega- 3 fatty acids that are good for cardiovascular system. Omega- 3 fatty acids are the type that our body cannot manufacture naturally, but they have to be taken in diet or supplements. Omega-3 fatty acids are actually the beneficial type of fat that can decrease the chances of heart issues, dementia, depression, vascular problems and skeletal deformities like arthritis. Some studies have suggested that the oils these seeds possess contain anti-inflammatory properties, some studies revealed role of $\alpha$-linolenic acid in reversing the hardening of blood vessels (Atherosclerosis) ${ }^{7-8}$. As the seeds contain jelly-like product upon soaking, these help in maintaining better digestive condition and are helpful for avoiding constipation. Also they help in better nutrient absorption in the intestine during food digestion which offers better health. Basil seeds are said to have antioxidants that make them even more good choice for the balanced diet. As antioxidants play important role in detoxifying the body by filtering it from harmful substances ${ }^{9}$.

Earliest studies have found several parts of Ocimumbasilicum to show a variety of effects including improvement of lipid metabolism in hypercholesterolemicrats ${ }^{10}$. However, most work has been done on oil or aqueous extracts of whole plant ${ }^{11}$. Little has been reported regarding seeds effects alone. More extensive studies are needed to explore potential therapeutic effects. Likewise Chia has bioactive potential and previous reports have indicated that its daily consumption may reduce the risk of disease progression, primarily due to the antioxidant, 
anti-inflammatory and hypolipidemic ${ }^{12}$. Nevertheless, seeds of both plants resembles closely in appearance and in their aqueous behavior.

Salvia hispanica (Chia seeds) and Ocimumbasilicum (Basil seeds) were studied in this research. Effects of these seeds were studied in Albino mice after raising their cholesterol levels by fatty diet. The purpose was to observe the effects of seeds on lowering blood cholesterol and burning body fats in Albino mice. In folklore, Ocimumbasilicum (Basil seeds) are said to have properties of weight loss, better digestion and other health benefits. While Salvia hispanica (Chia seeds) were considered as calcium rich. In this research the hypolipedemic properties of both seeds were compared with a standard drug atorva.

\section{MATERIALS AND METHODS}

Study groups of animals: Total 42 Swiss Albino mice with average weight $22-27 \mathrm{~g}$ were used in this research, these were distributed into different groups at random. First group was standard control group; other 6 groups were fed on fatty diet (dose made by mixing Triton-X-100 $(100 \mathrm{mg} / \mathrm{kg})$ in normal saline solution) for two weeks to raise their blood cholesterol.Afterwards, one of the 7 groups was kept untreated (hyperlipidemia group), while four groups were treated with $200 \mathrm{mg}$ and $400 \mathrm{mg}$ dose of Basil and Chia seeds extracts, respectively in addition to normal diet. Standard control group was given normal feed, water and drug atorvastatin $(100 \mathrm{mg} / \mathrm{kg} /$ day $)$. Conventional steel cages were used to keep mice under a 12 hours light/dark cycle and at $25 \pm 1^{\circ} \mathrm{C}$. The eating behavior and body weight were monitored daily and weekly, respectively. All experiments were performed in compliance to standard guidelines for use of laboratory animals.

Collection of Seeds and extract preparation: Extracts of Chia seeds (Salvia hispanica) and Basil seeds (Ocimumbasilicum) were used as experimental dosages. Briefly, Basil and Chia Seeds (Ocimumbasilicum and Salvia hispanica) were grinded to fine powder and soaked in 2 Liters of analytical grade methanol for maceration. After filtration through Whatmann1 Filter paper.After evaporation, the residues were dried and soaked again into $1 \mathrm{~L}$ of distilled water to obtain aqueous extracts of the seeds. After three days, the filtrates were obtained that further evaporated by rotary evaporator. The seeds extracts thus obtained were stored at $4{ }^{\circ} \mathrm{C}$ in airtight containers. Percentage yield for methanol was $17 \%$.

Collection of Blood samples and Lipid profile analysis: After completion of 45 days, blood samples were taken by cardiac puncture under mild chloroform anesthesia. The mice were kept fasting overnight. Plasma was separated from collected blood and analyzed for total cholesterol, triglycerides, LDL and HDL with the help of commercial kits of Human, Germany.

Histological studies:Euthanized animal liver and hearts were weighed, tissue samples were analyzed for histological analysis.The standard procedure of Hematoxylin and eosin staining was performed to study general morphology.

Statistical analysis:Data analysis was performed on Prism 7 (GraphPad). The values were reported as mean \pm standard deviation (SD).T-test of Student was applied to find statistical significance among groups. The significant difference at $\mathrm{P}<0.05$ was considered.

\section{RESULTS}

Before the start as well as throughout the experiment all animals were monitored for food intake, weight gain/loss and physical activities. After thirty days of mice extract feeding, $200 \mathrm{mg} / \mathrm{kg}$ groups of Chia and Basil showed slight but no significant decrease in mice body weight. While $400 \mathrm{mg} / \mathrm{kg}$ dose groups were comparatively, a little more effective as shown in figure 1. Chia dose groups showed minute difference among two doses, while basil dose groups also showed a very small decrease in weight.

Body weights were measured again on $45^{\text {th }}$ day and reduction in animal weightof $200 \mathrm{mg} / \mathrm{kg}$ and $400 \mathrm{mg} / \mathrm{kg}$ dose groups of Chia and Basilwas observed. The graphical description of differences among the groups that were administered with hyperlipidemia and afterwards with doses of Chia and Basil extracts is shown in figure 1.

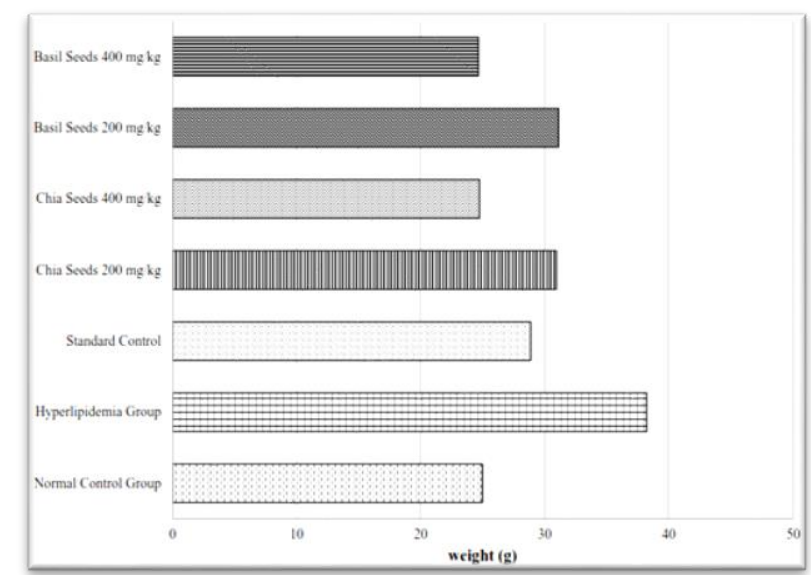

Figure 1: Effect of Chia Seeds and Basal Seeds Extracts on Body Weight in Mice after 45 days of treatment.

Plasma levels of cholesterol, lipoproteins and triglycerides at the end of experiment for each group has been described in table1. Levels of cholesterol, HDL, triglycerides, LDL and VLDL were much higher in Hyperlipidemia group $(247.69 \pm 2.6, \quad 20.47 \pm 2.97$, $206.19 \pm 7.40,191.05 \pm 4.63,51.99 \pm 1.37$ respectively), while they were low among seed extract treated groups. Dose of $400 \mathrm{mg} / \mathrm{kg}$ of Chia and Basil was more effective as compared to the $200 \mathrm{mg} / \mathrm{kg}$ doses. Moreover, while comparing $400 \mathrm{mg} / \mathrm{kg}$ dose, mice having Basil seed extract showed more reduction in plasma cholesterol level to that of Chia group. LDL levels in which $400 \mathrm{mg} / \mathrm{kg}$ doses for Chia and Basil show a very significant decrease over $200 \mathrm{mg} / \mathrm{kg}$ doses.

Triglyceride levels in plasma were significantly higher in hyperlipidemic mice group than those of normal control mice $(178.2 \pm 47.1$ vs. $52.0 \pm 26.0 \mathrm{mg} / \mathrm{dl}, 128.9 \pm 27.0$ vs. $83.7 \pm 11.5 \mathrm{mg} / \mathrm{dl}$, respectively). After 45 days of seeds extract treatment, triglyceride levels in the plasma decreased significantly as well as in dose dependent manner. Triglyceride levels in the plasma of diet supplemented groups with $200 \mathrm{mg} / \mathrm{kg}$ and $400 \mathrm{mg} / \mathrm{kg}$ Basil 
seeds extracts were $171.44 \pm 1.08$ and $103.71 \pm 3.02$ respectively(Table 1).

Histopathology staining and microscopy showed normal pattern of cellular structure in cardiac cells of mice after treatment with seeds extract. Moreover, normal pattern of cellular structure in hepatic cells of seed extract treated mice were observed. No sign of cardio-toxicity and hepatotoxicity was observed (Figure 2).

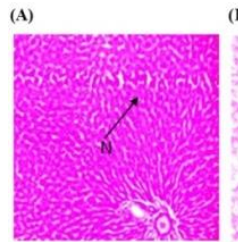

(D)

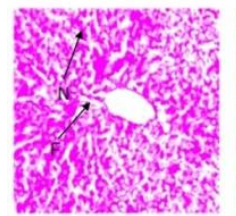

(G)

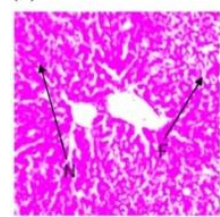

Figure 2: Histological photomicrographs (H \& E X 200) of hepatic tissues of mice, $(A)=$ Normal Control,

(B) = Hyperlipidemic Group, (C) = Standard Control, (D) Treated Control-1 (Chia Seeds $200 \mathrm{mg} / \mathrm{kg}$ ),

$(E)=$ Treated Control -2 (Chia Seeds $400 \mathrm{mg} / \mathrm{kg}$ ),

$(F)=$ Treated Control-3 (Basil Seeds $200 \mathrm{mg} / \mathrm{kg}$ ) and $(\mathrm{G})=$ Treated Control-4 (Basal Seeds $400 \mathrm{mg} / \mathrm{kg}$ ) ( $\mathrm{N}=$ normal cells, $\mathrm{F}=$ Fats deposited)

\section{DISCUSSION}

Obesity can cause many unwanted changes in body that can prove fatal. Obesity may result because of hyperlipidemia and in response hyperlipidemia may cause atherosclerosis. Natural products of plants possess many such hidden remedies that are a clear solution to our problems. Herbal treatments have always been used in practice since ancient times. Due to the reported sideeffects of pharmaceuticals, masses are turning toward herbal practices. Many effective medicines have plant origin. For example, Willow bark, Cinchona bark and Cinchona bark is the source of aspirin and quinine respectively. Many pharmaceutical companies still invest in screening of valuable herbs [2].

In this study, the oral supplementation of basil seed extract $400 \mathrm{mg} / \mathrm{kg} /$ day in mice reduced plasma cholesterol and triglycerides significantlycompared to a hyperlipidemic group $(78.25 \pm 1.51 \mathrm{mg} / \mathrm{dl}$ and $96.86 \pm 1.98 \mathrm{mg} / \mathrm{dl}$ vs. $247.69 \pm 2.62 \mathrm{mg} / \mathrm{dl}$ and $206.19 \pm 7.40 \mathrm{mg} / \mathrm{dl}$ respectively). The reduction in body weight in treated group mice were apparent from treatment day 30 , and then continued during the course of 45 days treatment period. This change in reduction in plasma cholesterol and triglycerides is very close to the effect in standard drug supplemented group $(95.14 \pm 3.14 \mathrm{mg} / \mathrm{dl}$ and $112.42 \pm 2.8 \mathrm{mg} / \mathrm{dl}$ respectively).

The hypolipidemic effect of chia and basil seeds could be due to omega-3. Omega-3 oil, present in both the seeds (Chia/basil). Omega-3 oil has many health benefits some of which are controlling LDL cholesterol, triglycerides, inflammation and helps to regulate many metabolic processes. Omega-3 oil contain long-chain unsaturated fats which are fundamental for weight control and can be arranged in 2 assemblies: in plant seeds, n-6 unsaturated fats and in marine vertebrates, $n-3$ unsaturated fats are usually found. In a study conducted on phytic acid showed same result. In an animal experiment, there was significant reduction in plasma cholesterol and HDL levels of the phytic acid-fed mice in contrast to high fed mice [13].

Additional proof of $n-3$ advantages to human wellbeing incorporate a recent report exhibiting a $29 \%$ decrease in lethal heart arrhythmias among subjects with an ongoing myocardial dead tissue who had been encouraged to devour fish oil.

Table1: Effect of Chia Seeds And Basil Seeds Extracts on Mice Plasma Lipid Profile

\begin{tabular}{|c|c|c|c|c|c|}
\hline Group category & Cholesterol(mg/ dl) & HDL(mg/ dl) & Triglycerides(mg/ dl) & LDL(mg/ dl) & VLDL(mg/ dl) \\
\hline Normal Group & $114.00 \pm 28.51$ & $42.82 \pm 1.73$ & $100.03 \pm 2.77$ & $73.08 \pm 1.23$ & $23.40 \pm 0.56$ \\
\hline Hyperlipidemia Group & $247.69 \pm 2.62^{\star *}$ & $20.47 \pm 2.97^{\star *}$ & $206.19 \pm 7.40^{\star *}$ & $191 \pm 4.63^{\star *}$ & $51.99 \pm 1.37^{* *}$ \\
\hline $\begin{array}{l}\text { Standard Control } \\
\text { (drug controlled) }\end{array}$ & $95.14 \pm 3.14 \mathrm{~ns}$ & $38.21 \pm 1.36^{*}$ & $112.42 \pm 2.8^{\star *}$ & $77.83 \pm 2.12^{*}$ & $30.78 \pm 1.12^{\star \star}$ \\
\hline $\begin{array}{l}\text { Treated-1 } \\
\text { (Chia Seeds } 200 \text { mg/kg) }\end{array}$ & $216.37 \pm 9.35^{\star \star}$ & $26.17 \pm 2.04^{* *}$ & $171.44 \pm 1.08^{* *}$ & $168.75 \pm 7.72^{*}$ & $46.45 \pm 1.65^{\star *}$ \\
\hline $\begin{array}{l}\text { Treated-2 } \\
\text { (Chia Seeds } 400 \text { mg/kg) }\end{array}$ & $84.32 \pm 1.86^{*}$ & $37.02 \pm 0.81^{\star *}$ & $103.71 \pm 3.02 \mathrm{~ns}$ & $71.04 \pm 3.33 \mathrm{~ns}$ & $32.17 \pm 1.33^{* *}$ \\
\hline $\begin{array}{l}\text { Treated -3 } \\
\text { (Basil Seeds } 200 \text { mg/kg) }\end{array}$ & $195.92 \pm 7.46^{\star *}$ & $25.66 \pm 1.89^{\star \star}$ & $160.9 \pm 9.03^{\star *}$ & $164.51 \pm 10.36^{* *}$ & $47.10 \pm 3.35^{\star \star}$ \\
\hline $\begin{array}{l}\text { Treated-4 } \\
\text { (Basil Seeds } 400 \text { mg/kg) }\end{array}$ & $78.25 \pm 1.51^{*}$ & $40.3 \pm 0.92^{*}$ & $96.86 \pm 1.98 \mathrm{~ns}$ & $73.81 \pm 2.62 \mathrm{~ns}$ & $28.33 \pm 1.99$ ** \\
\hline \multicolumn{6}{|c|}{$\begin{array}{l}\text { Data values are expressed as } \\
\text { Mean } \pm \text { SD }\end{array}$} \\
\hline
\end{tabular}


Subjects getting n-3 who along these lines had essentially more elevated amounts of eicosapentaenoic corrosive and docosahexaenoic corrosive in their red platelet layers demonstrated a more drawn out time to first cardiovascular defibrillators occasions and had a fundamentally lower relative danger of having an cardiovascular defibrillators occasion $(P=0.033)$. Thisinvestigation exhibit that fish oil unsaturated fats affect coronary illness ${ }^{14}$.

Only seeds ofOcimumbasilicum seeds extracts were evaluated in this study, the cholesterol lowing effects of whole plants have been reported previously in different models. Significant blood glucose levels reduction in normal $(p<0.01)$ and streptozotocin diabetic rats $(p<0.001)$ as well as decrease in plasma cholesterol and triglycerides levels in diabetic mice were reported using the aqueous extract of Ocimumbasilicum whole plant. The change in blood glucose was apparent even after a single oral administration ${ }^{15}$.

In another report, role of $O$. basilicum aqueous extractadministrationto high fat diet fed rats in significantly $(p<0.05)$ preventing increases in serum cholesterol, HDL and LDL was demonstrated ${ }^{16}$. Hicham et al.also reported a significant decrease on plasma cholesterol and triglyceride $(42 \%$ and $39 \%$, respectively)due to treatment of total aqueous extract of sweet basil plant aerial parts. They also proposed three possible ways of the hypolipidemiceffect: increase in hepatic LDL receptor activity due to phenolic compounds.Furthermore, flavonoids famous role to reduce cholesterol synthesis.Lastly, inhibition of a prominent enzyme, acyl CoA cholesterol acyl transferase in cholesterol metabolism ${ }^{17}$. So, lipid controlling effects of $O$. basilicum seeds extract are in accordance with the previously reported whole plant extract effects. However, for better understanding of therapeutic potential, animal experiment of extended treatment period and advance assays is needed.

\section{CONCLUSION}

The current study evaluated the use of Salvia hispanica (Chia seed) and Ocimumbasilicum (Basil seed) for controlling hyperlipidemia. The net result of the research is positive regarding the use of Salvia hispanica (Chia seed) and Ocimumbasilicum (Basil seed) as shown by reduction in body weight and low blood lipid profile. Histopathological results cleared the doubts regarding toxicity, during the research the extracts of the plants did not shown any toxic effect on vital organs. $200 \mathrm{mg} / \mathrm{kg}$ doses shown lesser reduction rates over LDL, VLDL, cholesterol but they controlled the weights from elevating further. $400 \mathrm{mg} / \mathrm{kg}$ doses prove very effective over these parameters also on weight regulation. Dietary supplements in the management of hyperlipidemia. Among Chia and Basil, Basil seeds extract was more effective than Chia.

Conflict of Interest statement: The authors declare that there are no conflicts of interest.

\section{REFERENCES}

1. Wang $\mathrm{H}$, Naghavi $\mathrm{M}$, Allen $\mathrm{C}$, et al. Global, regional, and national life expectancy, all-cause mortality, and causespecific mortality for 249 causes of death, 1980â 2015: a systematic analysis for the Global Burden of Disease Study 2015 [J]. The Lancet, 2016, 388(10053):1459-544.

2. Vickers $A$ and Zollman $C$. ABC of complementary medicine: homoeopathy [J]. BMJ: British Medical Journal, 1999, 319(7217):1115.

3. Helal A, Tagliazucchi D, Verzelloni E, et al. Bioaccessibility of polyphenols and cinnamaldehyde in cinnamon beverages subjected to in vitro gastro-pancreatic digestion [J]. Journal of Functional Foods, 2014, 7:506-516.

4. Labra $M$, Miele $M$, Ledda $B$, et al. Morphological characterization, essential oil composition and DNA genotyping of Ocimumbasilicum L. cultivars [J]. Plant science, 2004, 167(4):725-731.

5. Muñoz LA, Cobos A, Diaz O, et al. Chia seed (Salvia hispanica): an ancient grain and a new functional food [J]. Food reviews international, 2013, 29(4):394-408.

6. Bushway AA, Belyea PR, Bushway RJ. Chia seed as a source of oil, polysaccharide, and protein [J]. Journal of Food Science, 1981, 6(5):1349-1350.

7. da Silva BP, Anunciação PC, da Silva Matyelka JC, et al. Chemical composition of Brazilian chia seeds grown in different places. Food chemistry, 2017,221:1709-1716.

8. da Silva BP, Toledo RC, Grancieri M, et al. Effects of chia (Salvia hispanica L.) on calcium bioavailability and inflammation in Wistar rats [J]. Food Research International, 2019, 116:592-599.

9. Mohammadi $\mathrm{A}$ and Oshaghi EA. Effect of garlic on lipid profile and expression of LXR alpha in intestine and liver of hypercholesterolemic mice [J]. Journal of Diabetes \& Metabolic Disorders, 2014, 13(1):20.

10. Harnafi H, Aziz M, Amrani S. Sweet basil (Ocimumbasilicum L.) improves lipid metabolism in hypercholesterolemic rats. e-SPEN, the European e-Journal of Clinical Nutrition and Metabolism [J]. 2009, 4(4):181-6.

11. Bilal A, Jahan N, Ahmed A, et al. Phytochemical and pharmacological studies on Ocimumbasilicum Linn-A review [J]. International Journal of Current Research and Review, 2012, 4(23).

12. Enes BN, Moreira LP, Silva BP, et al. Chia seed (Salvia hispanica L.) effects and their molecular mechanisms on unbalanced diet experimental studies: A systematic review [J]. Journal of Food Science, 2020, 85(2):226-239.

13. Kang MY, Kim SM, Rico CW, et al. Hypolipidemic and antioxidative effects of rice bran and phytic acid in high fatfed mice [J]. Food Science and Biotechnology, 2012, 21(1):123-128.

14. Leaf A. Historical overview of $n-3$ fatty acids and coronary heart disease [J]. The American journal of clinical nutrition, 2008, 87(6):1978-1980.

15. Zeggwagh NA, Sulpice T, Eddouks M. Anti-hyperglycaemic and hypolipidemic effects of Ocimumbasilicum aqueous extract in diabetic rats [J]. American journal of Pharmacology and toxicology, 2007, 2(3):123-129.

16. Umar IA, Mohammed A, Dawud FA, et al. The hypolipidemic and antioxidant actions of aqueous extracts of Ocimumbasilicum and Ocimum suave in high fat fed Rats [J]. J Med Plants Res, 2012, 6(18):3501-3505.

17. Hicham $H$, Mohammed A, Souliman A. Sweet basil (Ocimumbasilicum L.) improves lipid metabolism in hypercholesterolemic rats J [J]. Clinic. Nutr. Metab, 2009, 4:181-186. 